\title{
ORANG TUA SEBAGAI PANUTAN ISLAMI ANAK
}

\section{PARENTS AS AN ISLAMIC ROLE MODEL FOR KIDS}

\author{
Zahra Khusnul Lathifah ${ }^{1}$, Fachri Helmanto ${ }^{2 a}$ \\ ${ }^{1}$ Manajemen Pendidikan, Fakultas Keguruan dan Ilmu Pendidikan \\ Jl Pintu Tol Ciawi no 1, Universitas Djuanda \\ ${ }^{2}$ Pendidikan Guru Sekolah Dasar, Fakultas Keguruan dan Ilmu Pendidikan \\ J1 Pintu Tol Ciawi no 1, Universitas Djuanda \\ Korespondensi: 081311651185 email: fachri.helmanto@ unida.ac.id
}

\begin{abstract}
The development of information technology, smartphones, are already familiar to children. Parents often use Youtube video applications on smartphones to control children's emotions. Children who are accustomed to using a smartphone tend to give $2^{\text {nd }}$ priority to their obligations as a Moslem. This study aims to determine the efforts of parents to introduce Moslem's obligation. The methodology used in this research is a case study with a narrative approach. The research was conducted on 32 of $5^{\text {th }}$ graders students in primary at Sekolah Dasar Negeri Citapen 01, Kabupaten Bogor. Data obtained through a questionnaire, observations, and interviews which were analyzed by grouping empirical data to find out data generalizations. The results showed $96.9 \%$ of children felt parents had set a role model in speaking good words. Physical behavior that can be visually seen can be easily followed by children, while verbal behavior required a separate technique. This research is limited by the role of parents in communication the obligation of a Moslem. Parents are advised to allocate time with children to introduce Moslem's Obligations of daily prayers and understanding merit and sin.
\end{abstract}

Keywords: Islamic role model, Moslem's obligation, Islamic character education

\section{ABSTRAK}

Perkembangan teknologi informasi, smartphone, sudah tak asing digunakan oleh anak-anak. Orang tua sering kali menggunakan aplikasi video Youtube pada smartphone untuk mengendalikan emosi anak. Anak yang terbiasa menggunakan smartphone memiliki kecenderungan menomorduakan kewajibannya sebagai seorang muslim. Penelitian ini bertujuan mengetahui upaya orang tua memperkenalkan kewajiban seorang muslim. Metodologi yang digunakan dalam penelitian ini adalah studi kasus dengan pendekatan naratif. Penelitian ini dilakukan pada 32 anak kelas 5 sekolah dasar di SDN Citapen 01, Kabupaten Bogor. Data yang diperoleh melalui angket. observasi dan wawancara dianalisa dengan mengelompokan data empiris untuk mengetahui generalisasi data. Hasil penelitian menunjukan 96,9\% anak merasa orang tua telah memberikan teladan dalam bertutur kata yang baik. Perilaku fisik yang tampak secara visual dapat diikuti anak, sementara perilaku yang bersifat verbal memerlukan teknik tersendiri. Penelitian ini dibatasi dengan peranan orang tua dalam mengomunikasian kewajiban seorang muslim. Orang tua disarankan perlu mengalokasikan waktu bersama anak-anak untuk memerkenalkan kewajiban seorang muslim yakni mengenalkan doa-doa harian dan pemahaman atas pahala dan dosa.

Kata Kunci: panutan islami, kewajiban muslim, pendidikan karakter Islam

Lathifah, ZK \& Helmanto, F. Orang Tua Sebagai Panutan Islami Anak. Didaktika Tauhidi:

Jurnal Pendidikan Guru Sekolah Dasar, 6(2), 131-137 


\section{PENDAHULUAN}

Pendidikan 4.0 merupakan fenomena kelanjutan dari revolusi industri 4.0 (Rojko, 2017). Pendidikan 4.0 ini merujuk pada penggunaan perangkat ICT secara ekstensif yang berorientasi pada koneksi jaringan internet. Perangkat yang paling mudah dijumpai dan lebih sering dilihat serta mudah digunakan salah satunya adalah smartphone. Smartphone memiliki peranan yang bernilai positif bagi pendidikan (Ismail, Azizan, \& Azman, 2013). Alih-alih untuk pengenalan teknologi pada anak, smartphone menjadi tren baru dalam pendidikan di keluarga. Penggunaan smartphone, kini, mudah dijumpai semenjak usia anak 3 tahun. Beberapa pertimbangan orang tua yang memberikan smartphone kepada anaknya didominasi oleh pengalihan fokus anak agar tak mudah jenuh selama dalam perjalanan jauh. Adapun hal lainnya, orang tua lebih membutuhkan waktu istirahat sepulang kerja dibanding bermain bersama anaknya (Utami, 2013).

Sewajarnya, orang tua tetap berperan sebagai sumber pendidikan bagi anak (Taubah, 2015). Pendidikan pertama dan utama anak diawali sejak anak berada di lingkungan keluarga, khususnya didominasi oleh peranan sang ibu. Secara intensif, ibu memberikan contoh kehidupan keseharian anak di rumah, termasuk pemberian contoh atas nilai-nilai ajaran Islam. Anak-anak pun mampu menerima fakta keberadaan ibu lebih banyak dibanding ayah (Wiese \& Freund, 2011). Tak dipungkiri bahwa dewasa ini, beberapa wanita memilih ikut bekerja membantu suami untuk ikut menopang kehidupan perekonomian keluarga. Pemilihan sikap tersebut memicu frekuensi anak atas penggunaan smartphone yang tidak dikontrol.

Sekolah Dasar Negeri (SDN) Citapen 01 kelas 5 memiliki kedua orang tua murid sebanyak 62,5\% sebagai pekerja. 20 dari 32 siswa memiliki waktu bersama orang tua hanya di waktu sore dan malam saja. Berdasarkan data awal tersebut, penelitian ini diinisasikan untuk mengetahui sejauh mana peranan orang tua dalam mengenalkan kewajiban anak sebagai seorang muslim yang mampu mengamalkan nilai-nilai ajaran Islam.

\section{METODE}

Metode studi kasus dengan pendekatan kualitatif digunakan dalam penelitian ini. Karakteristik studi kasus dapat mengakomodir fenomena sosial dalam lingkup kecil dan mampu mengungkap sebuah fenomena tersebut secara mendalam (Kothari, 2004; Stake, 2010). Objek penelitian ini adalah 32 orang peserta didik kelas 5 di SDN Citapen 01 J1 Veteran No. 1, 
Desa Citapen, Kabupaten Bogor. Data penelitian ini menggunakan angket sebagai data primer. Uji validitas angket tersebut, lalu, menggunakan uji konten, uji validitas kriteria dan uji konstruksi (Kothari, 2004). Kemudian, uji reliabilitas dilakukan pada kelas lain yang sejenjang dan diukur melalui uji koefisien Cronbach's alpha yakni $\alpha=0,556$. Hasil pengujian validitas dan reliabilitas tersebut menghasilkan 9 butir pertanyaan yang disajikan kepada objek penelitian. Observasi dan wawancara, selanjutnya, digunakan untuk melakukan konfirmasi atas temuan data empiris angket yang telah diberikan. Ketiga jenis data yang diperoleh kemudian dikelompokan untuk mencari generalisasi atas fenomena yang selanjutnya dapat dikatakan sebagai temuan atas penelitian ini.

\section{HASIL}

Angket penelusuran peranan orang tua dalam memperkenalkan kewajiban dengan bertutur kata yang baik. Hal itu dapat dilihat dari tabel 1 berikut dibawah ini.

Table 1

\begin{tabular}{lcccc}
\hline \multicolumn{1}{c}{ Kewajiban } & Selalu & Sering & Jarang & $\begin{array}{c}\text { Tidak } \\
\text { Pernah }\end{array}$ \\
\hline $\begin{array}{l}\text { bertutur kata } \\
\text { yang baik }\end{array}$ & 96,9 & 3.1 & 0 & 0 \\
$\begin{array}{l}\text { mengajarkan } \\
\text { kejujuran }\end{array}$ & 87,5 & 9,4 & 3,1 & 0 \\
$\begin{array}{l}\text { memberikan } \\
\text { contoh } \\
\text { perilaku yang } \\
\text { baik }\end{array}$ & 93,8 & 3,1 & 3,1 & 0 \\
& & & & \\
\end{tabular}

\begin{tabular}{lcccc}
$\begin{array}{l}\text { mengajarkan } \\
\text { tanggung } \\
\text { jawab } \\
\text { mempraktikan }\end{array}$ & 87,5 & 9,4 & 3,1 & 0 \\
$\begin{array}{l}\text { tata cara } \\
\text { berwudhu } \\
\text { melakukan } \\
\text { solat lima }\end{array}$ & 65,6 & 25 & 6,3 & 3,1 \\
$\begin{array}{l}\text { waktu } \\
\text { mengajarkan } \\
\text { tadarus }\end{array}$ & 84,4 & 15,6 & 0 & 0 \\
$\begin{array}{l}\text { mengajarkan } \\
\text { doa harian } \\
\text { memberi }\end{array}$ & 68,8 & 31,3 & 0 & 0 \\
$\begin{array}{l}\text { pemahaman } \\
\text { atas pahala } \\
\text { dan dosa }\end{array}$ & 56,3 & 25 & 12,5 & 6,3 \\
\hline
\end{tabular}

\section{PEMBAHASAN}

Keluarga adalah wilayah pembentukan karakter anak pertama dan utama. Hal ini tentu saja dilandasi dengan kesadaran akan nilai-nilai yang ingin dikomunikasikan orang tua dalam pola asuh kepada anak misalnya nilai-nilai Islam. Tuntunan Islam dalam pendidikan keluarga menciptakan anak yang berakhlak baik (Ariah, 2015).

Pendidikan keluarga yang mengambil nilainilai agama Islam mengarahkan pola pendidikan bagi anak menjadi pendidikan Islam. Pendidikan Islam dilaksanakan dengan mengembangkan, mendorong, dan mengajak anak menjadi lebih baik setiap harinya; dengan berdasarkan keluhuran akhlak yang mulia; dan, dengan melibatkan seluruh potensi kognisi, afeksi dan psikomotor (Ainissyifa, 2014). Pendidikan Islam memiliki kesinambungan dari pendidikan keluarga, sekolah hingga ke 
masyarakat. Ketiganya merupakan integritas pendidikan yang diawali dan dipupuk dari lingkungan keluarga.

Ayah dan Ibu memiliki sejumlah peranan penting dalam pengomunikasian nilai-nilai Islam. Islam sebagai ajaran yang mampu mengatur manusia secara terperinci memiliki sejumlah kewajiban yang dapat mengindikasikan pencapaian anak sebagai muslim yang baik. Kewajiban anak sebagai muslim yang dapat diajarkan oleh orang tua antara lain 1) tutur kata yang baik; 2) kejujuran; 3) contoh perilaku yang baik; 4) tanggung jawab; 5) cara berwudhu; 6) solat lima waktu; 7) tadarus; 8) doa harian; 9) pahala dan dosa.

Pembelajaran tutur kata yang baik dilaksanakan oleh orang tua yang banyak dilakukan oleh para ibu. Interaksi ibu setiap hari yang menanyakan beragam hal dari sang anak bangun tidur di pagi hari hingga anak kembali tidur di malam hari. Tutur kata yang bersifat transaksional misalnya “sudah bangun, ya?", "segera mandi, lalu ambil wudhu dan solat!” dan lain sebagainya. Pembelajaran tutur kata baik yang senantiasa diperdengarkan dengan baik kepada anak memicu anak untuk selalu membalas tutur kata ibunya dengan baik pula.

Pembelajaran kejujuran pada anak dilaksanakan dengan konsistensi orang tua dalam bersikap dan berperilaku. Orang tua membiasakan dirinya untuk bersikap jujur atas apapun yang dialami misalnya mengakui kesalahan atau kekhilafan saat lupa membelikan makanan yang dipesankan anak.

Pembelajaran kejujuran beririsan dengan pembelajaran tanggung jawab pada anak. Kesalahan yang telah diakui sebaiknya segera diperbaiki. Tindakan memperbaiki kesalahan adalah bentuk sederhana dari sikap bertanggung jawab.

Setiap kali dirumah, orang tua senantiasa berupaya mengajak serta anak dalam melakukan salat berjamaah yang diawali dengan wudhu bersama dan dialnjutkan dengan solat serta diakhiri dengan doa.

Dalam kegiatan apapun, orang tua membacakan doa dengan nyaring agar doa tersebut dapat diperdengarkan dengan anak dan memberikan kesempatan anak untuk ikut doa bersama dengan menuturkan doanya dengan nyaring.

Pengalokasian waktu 5 hingga 10 menit setiap hari untuk membaca Quran atau tadarus juga turut serta memberikan contoh aplikatif yang dapat ditiru anak. Terlebih usai tadarus, orang tua mampu memberikan pemahaman atas ayat-ayat suci Quran yang dibaca dan dikaitkan dalam lingkup pahala dan dosa 
Dengan kata lain, sembilan hal tersebut dapat diajarkan orang tua melalui pendidikan yang terencana. Orang tua memosisikan diri sebagai sosok yang dapat ditiru oleh anak (Ainissyifa, 2014; Taubah, 2015) diawali dengan peniruan tutur (Ayuni \& Setiawati, 2019). Sejumlah aktivitias religi orang tua yang disaksikan anak di rumah juga akan ditirukan. Peniruan yang dilakukan anak didasari kesenangan atas pembelajaran budaya yang berkembang di lingkungan kehidupan kesehariannya (Blight, 2012).

Orang tua sebagai panutan dalam perspektif Islam juga memiliki kendala dan hambatannya tersendiri. Dengan berkembang pesatnya teknologi komunikasi, tidak semua kewajiban anak sebagai muslim berhasil dikomunikasikan orang tua. Kewajiban yang tampak lewat perilaku orang tua sangat mudah dikomunikasikan. Sementara kewajiban yang bersifat verbal seperti menghapal doadoa harian dan ajakan dialog perihal pahala dan dosa mengalami kesulitan untuk dikomunikasikan

\section{KESIMPULAN}

Pendidikan Islam mendahulukan pendidikan karakter yang dilandasi dengan akhlak yang baik dan mulia. Pendidikan karakter ini diawali dari pendidikan keluarga yang diperankan oleh orang tua.
Tak dapat dihindari perkembangan teknologi juga turut andil dalam proses pendidikan karakter. Meskipun begitu, anak tetap menjadikan orang tua sebagai panutan melalui peniruan-peniruan perilaku yang didominasi dari perbuatan keseharian yakni, bertutur kata yang baik, solat lima waktu, jujur, dan bertanggung jawab. Disamping itu, anak mengalami kesulitan dalam penerimaan pendidikan yang bersifat verbal antara lain mempelajari doa-doa harian dan dialog pemahaman atas pahala dan dosa.

Pendidikan Islam pada anak sewajarnya akan berlanjut pada pendidikan sekolah dan masyarakat. Segala yang telah dipelajari dirumah dari peniruan orang tua yang menjadi panutan dasar Islami sang anak akan diperkaya melalui kegiatan pembelajaran di sekolah dan di masyarakat. Oleh karena itu, penelitian selanjutnya disarankan menemukan sosok panutan Islami di lingkungan sekolah dan di masyarakat.

\section{DAFTAR PUSTAKA}

Ainissyifa, H. (2014). Pendidikan Karakter dalam Perspektif Pendidikan Islam. Jurnal Pendidikan Unversitas Garut, 8(1), 1-26.

Ariah. (2015). Pembentukan Karakter Kemandirian Siswa Melalui Implementasi Islamic Full Day School. Didaktika Tauhidi, 3(2), 121- 
128.

Ayuni, D., \& Setiawati, F. A. (2019). Kebun Buah Learning Media for Early Childhood Counting Ability. Jurnal Obsesi : Jurnal Pendidikan Anak Usia Dini, 3(1), 1. https://doi.org/10.31004/obsesi.v3i1.1 28

Blight, M. (2012). Cultures education in the primary years: Promoting active global citizenship in a changing world. Journal of Student Engagement: Education Matters, 2(1), 49.

Ismail, I., Azizan, S. N., \& Azman, N. (2013). Mobile phone as pedagogical tools: Are teachers ready?

International Education Studies, 6(3), 36-47.

https://doi.org/10.5539/ies.v6n3p36

Kothari, C. R. (2004). Research Methodology: Methods and Techniques. New Delhi: New Age International Publishers.

Rojko, A. (2017). Industry 4.0 concept:
Background and overview. International Journal of Interactive Mobile Technologies, 11(5), 77-90.

Stake, R. E. (2010). Qualitative Research: Studying How Things Work. New York: The Guilford Press.

Taubah, M. (2015). Pendidikan Anak dalam Keluarga Perspektif Islam. Jurnal Pendidikan Agama Islam, 3(1), 110-136.

Utami, K. W. (2013, June 29). Banyak Orang Tua Andalkan Gadget untuk "Mengasuh" Anak. Kompas. Com. Retrieved from https://lifestyle.kompas.com/read/201 3/06/29/1703028/Banyak.Orangtua.A ndalkan.Gadget.untuk.Mengasuh.Ana $\mathrm{k}$

Wiese, B. S., \& Freund, A. M. (2011). Parents as Role Models: Parental Behavior Affects Adolescents' Plans for Work Involvement. International Journal of Behavioral Development, 35(3), 218-224. https://doi.org/10.1177/01650254113 98182 